\title{
Solar power and policy powerlessness - perceptions of persuasion in distributed residential solar energy policy development
}

\author{
Genevieve Simpson* \\ School of Agriculture and Environment, University of Western Australia, Crawley, Australia
}

Received: 16 January 2017 / Received in final form: 9 July 2017 / Accepted: 27 July 2017

\begin{abstract}
Distributed residential solar energy (photovoltaic) technologies have been praised as a mechanism to not only increase the penetration of renewable energy but engage the community in a clean energy revolution. In spite of this it is unclear how much potential there is for stakeholders to influence processes around the adoption of solar energy, including policy development and regulation. As part of a wider research project assessing the social acceptance of residential solar energy in Western Australia a variety of stakeholders, including public servants, network operators, Members of Parliament, energy advocates, renewable energy industry members and community members, were asked whether they thought they had the potential to influence solar policy. The objective of this research was to highlight positions of influence over policy development. In total 23 interviews with regional Western Australian householders and 32 interviews with members of industry and government were undertaken between May and October 2015. Most respondents believed that they had previously, or could in future, influence solar policy by taking advantage of networks of influence. However, stakeholders perceived as having policy influence did not necessarily demonstrate the capacity to influence policy beyond providing information to decision-makers, namely Cabinet members. Instead, networks of renewable energy advocates, industry and community members could apply political pressure through petitions, media coverage and liaising with parliamentarians to develop support for policy changes. Furthermore, while policies for the promotion of solar energy, and renewable energy more generally, could be implemented at various levels of government, only those policies delivered at the state level could address socio-political barriers to renewable energy adoption. These barriers include: a lack of political will and funding to overcome technical issues with network connection; reductions in fossil fuel subsidies to encourage an "even playing field"; and removal of regulatory barriers for innovative renewable energy solutions.
\end{abstract}

\section{Introduction}

Governments internationally have established policies for the promotion of renewable energy in order to meet emissions reduction targets. Australia, like many other nations, has instituted a number of financial and marketbased mechanisms to promote renewable energy investment, including a federal Renewable Portfolio Standard, the Renewable Energy Target [1], and state-based premium feed-in tariffs [2] to support residential solar energy adoption. In the absence of generous financial incentive policies, renewable energy adoption rates have slowed for both large-scale and small-scale systems, in spite of the efficient economic returns on system investment [3]. In particular, adoption rates for residential solar systems in Western Australia have not returned to peak levels

\footnotetext{
* e-mail: genevieve.simpson@research.uwa.edu.au
}

experiences during incentive-intensive periods (Fig. 1). Furthermore, surveys of residential solar customers have suggested that there are concerns about the trustworthiness of solar installers and suppliers, and a perceived insufficiency of reliable information to assist with solar adoption decision-making [4]. Wüstenhagen and Wolsink [5] suggest that adoption of renewable energy is not solely reliant on the sound economics of projects and technologies capable of reliably providing renewable energy, but is instead reliant on the social acceptance of renewable energy. The social acceptance of renewable energy can be separated into three dimensions: community acceptance, market acceptance and socio-political acceptance.

Community acceptance relates to the extent to which community members believe that they have been appropriately consulted in the development of renewable energy projects (procedural justice) and the extent to which the distribution of "goods" and "bads" accruing to community members is deemed acceptable. In the case of 


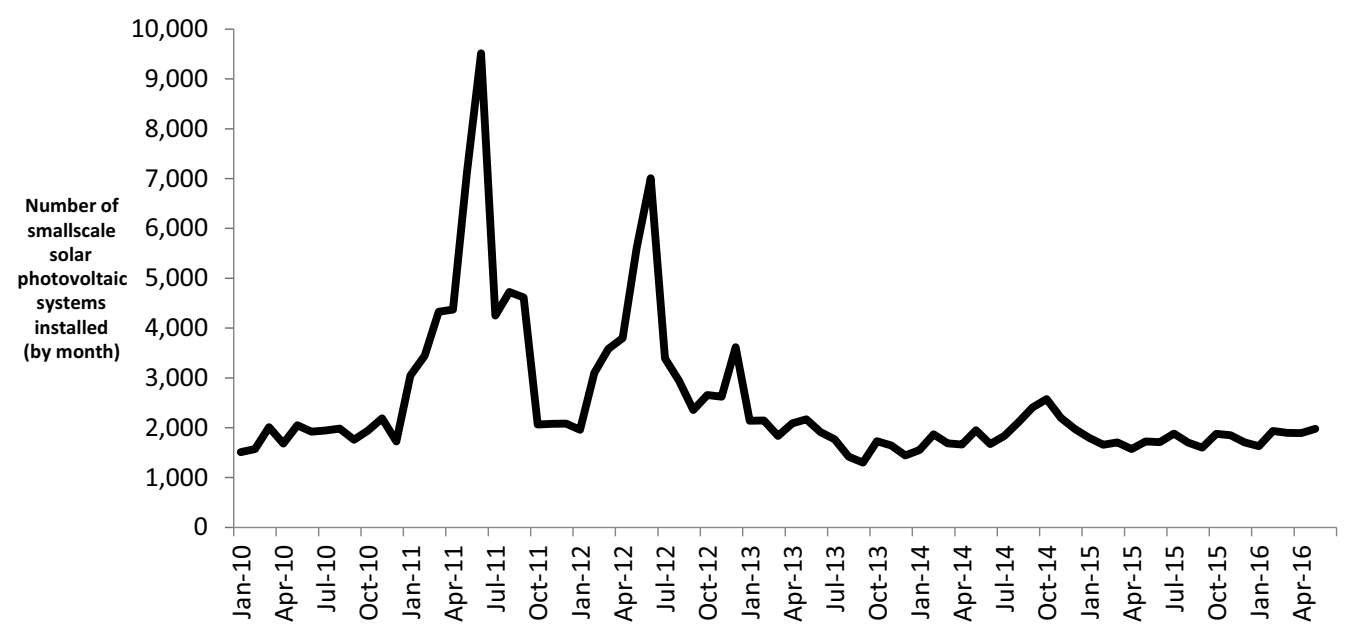

Fig. 1. Number of smallscale solar photovoltaic systems installed in Western Australia, indicating that installation rates have not returned to peaks experienced during incentive-intensive periods [6].

residential solar energy, research has examined the existence of regressive forms of taxation in the provision of financial incentives[2], and perceptions of these "transfers of wealth" [7]. Market acceptance relates to the extent to which investors are willing to fund renewable energy projects, which is in turn dependent on the extent to which investors perceive there to be reliable consumers or purchasers of renewable energy. Access to information has been found to be a barrier to investment in residential solar energy $[4,8]$. Finally, socio-political acceptance relates to the extent to which policies and key stakeholders, including the general public, are supportive of renewable energy innovation and its replacement of incumbent generation systems. The vast majority of research in renewable energy policy examines the role of market-based policies to support renewable energy investment, however Wolsink [9] demonstrates that facilitation of the adoption of residential solar energy (particularly in a smart grid setting) is reliant on the extent to which a socio-technical transition of technologies, institutions and stakeholders can overcome the "locked in" incumbent generation system.

In order to overcome the "locked in" system government policies must be responsive to the evolving needs of the new energy regime and resist maintenance of status quo policies that support the existing generation portfolio. In order for this responsiveness to manifest itself stakeholders should be given the opportunity to provide feedback on community, market or socio-political barriers to acceptance of renewable energy. Indeed, many policy development mechanisms now favour consultative processes for identifying persisting issues $[10,11]$. However, the various avenues for policy influence and their potential to impact on the social acceptance of renewable energy have not been studied. This paper seeks to fill this gap, with special reference to the adoption of distributed residential solar energy in regional Western Australia. This research asks whether stakeholders perceive themselves as having any influence on solar energy policy, the extent to which this influence is likely to result in changes to policy and which dimension of the social acceptance of renewable energy these policies focus on.
The policy-related support for renewable energy in Western Australia is worthy of analysis considering the myriad challenges and opportunities renewable energy, and in particular distributed solar energy, creates for the state[12]. The Western Australian Government has significant influence over policies and processes associated with the increased penetration of distributed generation considering its role in the generation, movement and sale of electricity. The three largest electricity utilities in Western Australia are government-owned, with ministerial oversight [13]. These are: the monopoly network operator in the South-West Interconnected System (the largest network in the state); the largest electricity retailer-generator in the state; and the regional electricity provider (generator, network operator and retailer), which provides electricity to 38 small regional grids/isolated power systems [14]. While there is competition within the electricity generation market the state-owned retailer-generator provides more than $50 \%$ of electricity sold in the South-West Interconnected System [15] and customers consuming less than $50 \mathrm{MWh}$ of electricity per annum are automatically customers of the state-owned retailer-generator [16]. The Western Australian Government also has oversight of the electricity regulator, the market operator, and the statebased public sector agency that has administered financial incentives for the promotion of renewable energy [17].

\section{Methodology}

The findings presented here are part of a larger body of research considering the social acceptance of residential solar energy in Western Australia, from the perspective of community, industry and government stakeholders. The research sought to examine the difference in solar experiences between two regional communities, one with access to a regional isolated network and with an informal solar community organisation (Carnarvon, Western Australia) and the other with access to the large SouthWest Interconnected System and without an informal solar community organisation (Narrogin, Western Australia). 
Table 1. Stakeholders interviewed, by geographic region of influence.

\begin{tabular}{lccc}
\hline Stakeholder category & State-wide & Carnarvon & Narrogin \\
\hline Member of Parliament & 2 & 1 & 1 \\
Public sector & 6 & 1 & 1 \\
Local government & 0 & 2 & 2 \\
Renewable energy industry member & 2 & 2 & 5 \\
Network operator & 2 & 1 & 2 \\
Renewable energy advocacy representative & 2 & 0 & 0 \\
Community member & 0 & 12 & 11 \\
Total & 14 & 19 & 22 \\
\hline
\end{tabular}

These two regional communities had similar populations, industries and proportions of rental accommodation at the 2011 census [18].

The research methodology is consistent with that undertaken by Allen et al. [19], who researched the drivers, enablers, barriers and solutions to community renewable energy projects. In order to gain an understanding of perceptions of the development of socio-political, market and community acceptance of renewable energy, stakeholders with socio-political (government and public sector), market (renewable energy industry, network operator and renewable energy advocate), and community-based experiences were interviewed.

Community members were accessed after self-selecting for an interview on completion of surveys used in alternate studies [3,4,7]. Members of Parliament were chosen based on their association with the regional communities or renewable energy initiatives. Renewable energy industry players active in promoting or installing renewable energy systems, in particular solar systems, in the regional communities were also approached for an interview. Public servants involved in renewable energy policy delivery at the state level, economic development projects at the regional level and local government workers were also interviewed. Two members of a former renewable energy advocacy group were also asked to participate in the research. A full list of stakeholders interviewed is available in Table 1.

Semi-structured interviews with key stakeholders were undertaken to develop an understanding of perceptions and experiences around solar energy adoption, industry regulation and government policies in place to support the adoption of residential solar energy. Each semistructured interview concluded by asking stakeholders the following two questions:

- Do you think you have personally been able to influence solar policy? If yes, what policy did you influence and how? If no, do you think you could influence solar policy, and how?

- Do you think governments should promote the development of renewable energy, and what do you think that promotion should look like?

The responses to these questions were transcribed. The comprehensive notes taken during interviews were also surveyed for any evidence of interactions with other stakeholders that could have contributed to influencing policy.
NVivo [20] was used to thematically group the survey responses based on three areas of interest:

- the communication networks that stakeholders have used or would use when influencing policy outcomes;

- the potential for policy change implemented by stakeholders, based on interview responses;

- the kinds of policy changes proposed by different stakeholders.

The interview results provide evidence of the extent to which different stakeholders favour policies to promote socio-political, market or community acceptance, and whether particular stakeholder groups are more likely to be successful in encouraging effective changes to policy.

Interviews were undertaken between May and October 2015. The results provided here are a reflection of the stakeholders interviewed and do not necessarily represent the perspectives of the agency or organisation the stakeholders work for. This research received approval from The University of Western Australia Human Research Ethics Office. Accordingly, all interview subjects were ensured that their contribution to this research would remain anonymous.

\section{Results}

Interview participants provided responses that allowed the generation of a perceived policy influence network map (Fig. 2). The vast majority of respondents believed that they had influenced solar energy policy, or had the means to do so if they wished. However, interviews with stakeholders in political and policy positions identified that they did not have the influence over policy outcomes that other stakeholders, in particular community members, believed they did. The interview respondents prioritised a range of policy options for the promotion of renewable energy, some appropriate for addressing market acceptance of renewable energy and others for addressing socio-political barriers to adoption. It is noted that there is greater potential for policies addressing market acceptance to be delivered considering these can be actioned at the local level, while socio-political policies require state government support, and therefore the support of the Minister for Energy and Cabinet. 


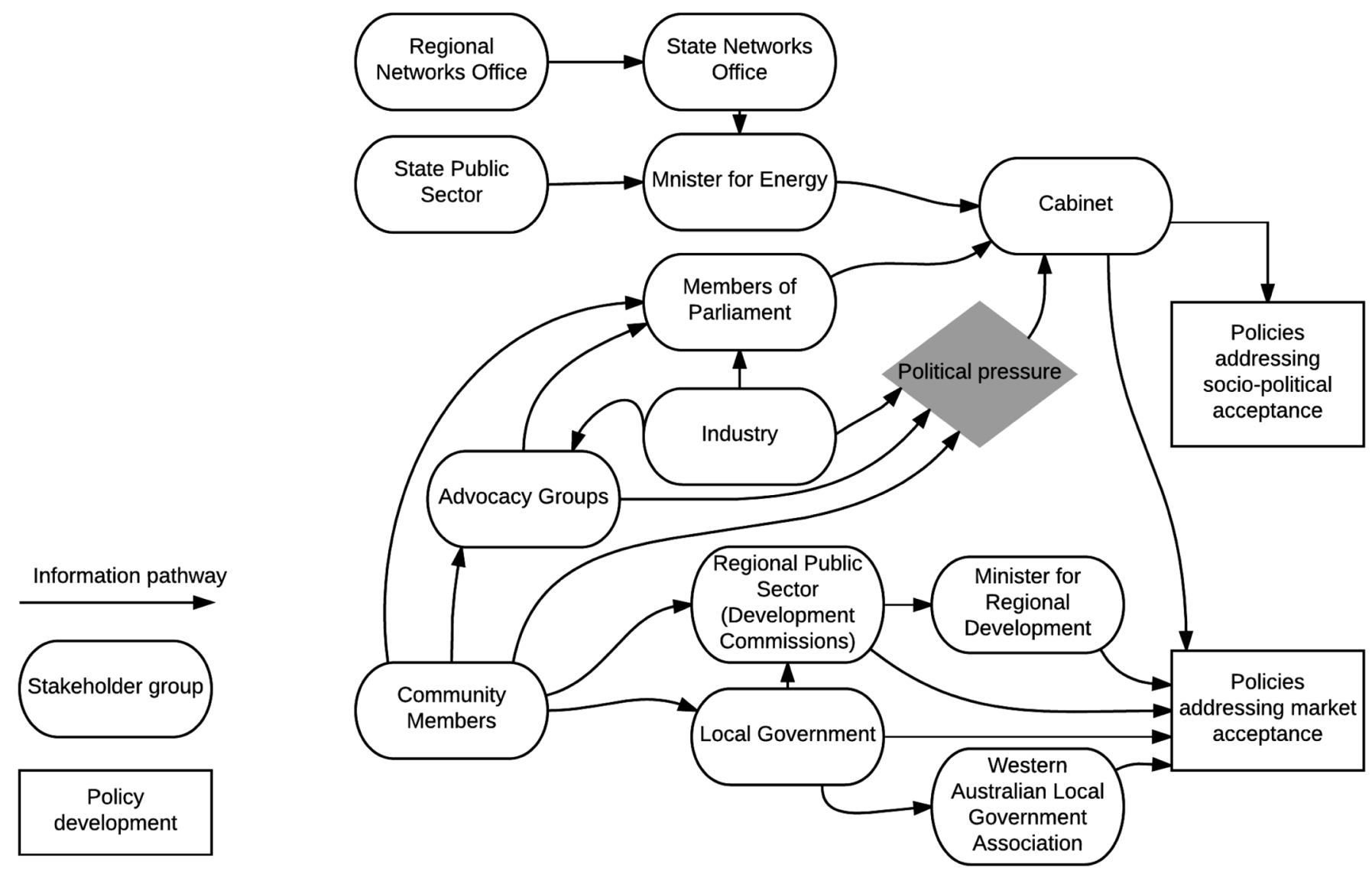

Fig. 2. Network map showing the pathways of policy influence suggested by interview respondents. Arrows represent opportunities for information exchange, however it is only at the point of "political pressure" that state government was considered likely to act on advice from stakeholders.

\subsection{Communication networks to influence policy outcomes}

The presence of a Member of Parliament in each of the regional communities meant householders had a direct communication link to Parliament. All but two of the community-based interview respondents indicated that they knew their local Member and could talk to them about policy issues if necessary. This was the most frequently stated outlet for accessing policy influence, followed by interactions with the local government or regional development commission. A small number of community members also raised an awareness of renewable energy advocacy groups, with householders signing petitions relating to renewable energy, including placing pressure on the government to maintain a high gigawatt hour target under Australia's Renewable Energy Target and maintain Western Australia's AU40 cent per kilowatt hour feed-in tariff. The advocacy groups Solar Citizens and Renewable Energy Now were both mentioned.

Neither public servants in the state public sector or the regional public sector indicated they had direct opportunities to influence policy considering policy decisions were made by their respective ministers and through their Department heads. Local government members did, however, have the opportunity to action policies. Local government members, while familiar with their Members for Parliament, did not suggest that they would seek to influence policy through them. Instead, local government members indicated that they could form alliances with other local governments and raise issues with the Western Australian Local Governments Association for development of a policy brief covering all local government areas.

Industry stakeholders sought out advocacy groups and Members of Parliament relevant to the location of their renewable energy projects to influence solar policy. In particular, the former Sustainable Energy Association, the peak advocacy group for renewable energy companies in Western Australia, was frequently mentioned. Representatives from advocacy groups interviewed for this research spoke to a wide range of industry players, from residentialscale to commercial-scale, and were considered effective in promoting the messages of the industry to the media and governments. These representatives had close networks with Members of Parliament, including Cabinet members.

\subsection{Potential for stakeholder-initiated policy changes}

While interview respondents identified stakeholders that they would seek out to influence policy the potential for these stakeholders to instigate change was in most cases limited. Members of Parliament interviewed indicated that they had few opportunities to influence policy unless they had a position on Cabinet, and even with a position on 
Cabinet the Minister for Energy or Premier made the majority of policy decisions. Instead, Members of Parliament indicated that their greatest influence on policy direction was through information provision. Members of Parliament sought to raise specific energy issues experienced by their constituents, or gain opportunities for renewable energy advocacy groups to be able to speak to Members of Parliament in positions of greater influence. Both Members of Parliament and the representatives from the former Sustainable Energy Association indicated that the Association was successful in driving an increased level of renewable energy knowledge in parliamentarians, with associated opportunities to influence the direction of government reviews.

Similarly, elected and unelected members of local government, although readily admitting that they could generate local government policies with renewable energy objectives, indicated that they could only do so with the will of the local community and local council behind them. Beyond taking advantage of opportunities to demonstrate the feasibility of renewable energy by installing demonstration solar systems on government buildings, local governments expressed an interest in providing renewable energy information to community members, developing local financial incentive policies or embedding sustainability (including renewable energy) objectives in their planning documents. However, local government members indicated that tight cash flows restricted them from resourcing information programs. Instead, an industry member in each community, the "solar champion" of the informal solar community organisation in Carnarvon and a self-proclaimed "Clean Energy Advocate" in Narrogin, acted independently to raise awareness about solar energy. Additionally, while both local governments expressed a desire to embed renewable energy goals in local planning documents, there was an awareness that such an action was a token gesture of good faith towards renewable energy ambitions and would not lead directly to investment. Instead, such documents would provide motivation for local governments to take advantage of opportunities to invest in renewable energy, where there was community and local council support and financial means available to do so. Wider-ranging policy ideas to be implemented by the Western Australian Local Government Association, for instance encouraging access to electric cars and solar charging stations for local government fleets, were also only considered possible with the support of local and neighbouring communities, and were also restricted based on budgets available.

State office-based network operators, state government public sector workers and regional public sector workers all believed they were in a position to influence policy. These stakeholders stated that they were able to provide feedback on regulations, policy processes and administrative functions to improve state energy policy outcomes. For example, these stakeholders said they were: able to suggest the implementation plan for financial incentives, influence the methodologies for determining fair residential solar energy buy-back rates, and identify and action potential policy issues associated with industry players with innovative business plans. It should be noted, however, that none of these stakeholders indicated that they had a discernible influence on the broader goals of government in relation to renewable energy policy. Instead, these decisions were solely the purview of Cabinet members, and in particular the Minister for Energy and the state Premier.

In all the cases mentioned above, stakeholders indicated that they had limited influence on solar policy decisions, and that any policy influence stemmed from opportunities to provide information to individuals in decision-making positions (generally members of Cabinet). Interview respondents did, however, mention two instances in which they believed they were able to influence the direction of policy by exerting political pressure on government. The first instance of political pressure was the culmination of stakeholders working together to mobilise support for a particular policy outcome. Renewable energy advocacy groups: mobilised a large number of industry players to support their policy direction (where the advocacy group was industry-focused); used social media to develop householder support for policies, evidenced in petitions being completed (where the advocacy group was community-focused); and undertook media campaigns. At the same time, advocacy groups and industry members took advantage of their networks with parliamentarians to advise them of the outcomes of proposed policy changes, in particular in terms of voter support. They also wrote directly to ministers responsible. Policy change was therefore the result of continuous exerted pressure from these groups. The prime example of such a policy shift was the state government's decision to reverse the 2013 budget announcement to reduce the premium feed-in tariff offered to householders installing solar systems prior to August 2011 [21]. The renewable energy advocacy representatives said that they immediately engaged with parliamentarians, in particular back benchers, highlighting public opposition to the reduction in the feed-in tariff. Almost 10,000 householders (metropolitan and regional) signed a petition opposing the policy to reduce the feed-in tariff [22], and many of the householders interviewed also raised the issue with their local parliamentarians, making it clear that they were considering changing their political allegiance in response to the policy. This all happened alongside an effective media campaign driven by advocacy groups and industry members.

The second example of influence over the direction of policy came from one member of the local solar industry in Carnarvon who believed that he had political influence outside of these industry/advocacy networks. This interview respondent held a position of authority in the town and was politically active, being a member of the local council and having previously run for state Parliament. He believed that his interactions with local and state government politics gave him the opportunity to access a large network of politicians, and inform their ideas on renewable energy policy. His role in the local solar industry also gave him the opportunity to liaise with the local network operator office about renewable energy connection issues. Finally, he used his influence over where votes he received flowed through in the preferential voting system as a lever for garnering political support for his solar policy ideas. 
Table 2. Potential policy approaches to promoting renewable energy suggested by respective stakeholder groups during interviews.

Member of Public Local
Parliament sector government

Industry Network Renewable operator energy advocacy member

\begin{tabular}{|c|c|c|c|c|c|c|c|c|}
\hline \multicolumn{9}{|l|}{ Market acceptance policies } \\
\hline $\begin{array}{l}\text { Promoting research and } \\
\text { development }\end{array}$ & 1 & 1 & - & 3 & - & - & 3 & 8 \\
\hline $\begin{array}{l}\text { Renewable demonstration } \\
\text { projects }\end{array}$ & 1 & 1 & 3 & 2 & - & - & 1 & 8 \\
\hline $\begin{array}{l}\text { Information provision to } \\
\text { community members }\end{array}$ & - & 5 & - & - & - & - & 9 & 14 \\
\hline $\begin{array}{l}\text { Market-based mechanisms } \\
\text { and incentives }\end{array}$ & 2 & 1 & - & 1 & - & 1 & 7 & 12 \\
\hline \multicolumn{9}{|c|}{ Socio-political acceptance policies (breaking the "lock-in") } \\
\hline $\begin{array}{l}\text { Consistency and transparency } \\
\text { in policies }\end{array}$ & - & - & 2 & - & 1 & - & 1 & 4 \\
\hline Remove fossil fuel subsidies & - & 3 & - & 2 & - & - & 1 & 6 \\
\hline Remove regulatory barriers & 2 & 5 & - & 3 & - & 2 & 2 & 14 \\
\hline Remove technical barriers & 1 & 3 & 3 & 2 & 2 & - & 4 & 15 \\
\hline $\begin{array}{l}\text { Increase regulation of } \\
\text { solar companies }\end{array}$ & - & 1 & - & & 2 & - & 2 & 5 \\
\hline
\end{tabular}

\subsection{Policy changes proposed by stakeholders}

The final question in the semi-structured interviews asked survey respondents whether they believed that governments should promote renewable energy and what this promotion should look like. While some survey respondents did not prioritise overt government "support" or "promotion" of renewable energy, all survey respondents were supportive of policy changes to improve the likelihood of increasing renewable energy penetration. According to the dimensions of social acceptance of renewable energy highlighted in the introduction, these policy approaches can be identified as those that seek to address market acceptance barriers and socio-political issues (Tab. 2).

The policies under the banner of "market acceptance policies" seek to make renewable energy resources more competitive with the incumbent energy system (financially and technically) and to improve community members" understanding of renewable energy. While many respondents stated during their interviews that solar and wind technologies are now technologically sound, several community members (all without their own solar system) indicated a lack of acceptance of the reliability of solar technology and suggested further research and development. These responses were similar to those identified in a survey of both regional and metropolitan Western Australian householders [7]. Industry members, public sector representatives and parliamentarians also prioritised funding to support research and development, however in this case research and development was aimed at improving Australian technologies to be competitive on the international stage. Stakeholders also suggested demonstration projects, particularly stakeholders in re- gional areas where larger-scale solar systems installed by either the local solar champion (Carnarvon) or the local council (Narrogin) were perceived as positively influencing local perceptions of solar energy. While parliamentarians and energy industry members did not identify information provision as a policy issue, both public sector workers and community members identified a lack of knowledge in the community as a significant barrier to solar adoption that could be addressed, which was in agreement with earlier findings [3,4]. Finally, stakeholders suggested a reintroduction of financial incentives to support residential adoption of solar systems (community members) or maintenance of market-based mechanisms to support renewable energy investment, such as Australia's Renewable Energy Target (other stakeholders). These policies all promote market acceptance of renewable energy by increasing the likelihood of consumers choosing to invest in renewable energy over continuing to use incumbent fossil-fuel generation sources.

Stakeholders also proposed policy options for increasing the socio-political acceptance of renewable energy, with interview respondents across all stakeholder groups identifying socio-political barriers to adoption in spite of Australia's generous financial incentives for renewable energy investment. Four interview respondents said that a lack of certainty (in terms of both consistency and transparency) in state and federal renewable energy policies was a barrier to adoption. Additionally, a large number of stakeholders, including five industry members, expressed a wish for what was referred to as "get out of the way" policies. Stakeholders suggested that some renewable energy technologies are now competitive with incumbent generation technologies. However, institutional "lock in" in government policies and decision-making still prioritises 
incumbents. In order to reduce this support, governments should seek to remove fossil fuel subsidies to create a "level playing field" and should remove regulatory barriers that limit the connection of renewable energy generation. In terms of regulatory barriers stakeholders mentioned regulations that prevented innovative solar purchasing programs and legislation that prevented network operators from owning battery assets that could facilitate higher intermittent renewable energy penetration. The largest group of interview respondents suggested that policies should address technological barriers to connection. This was likely the result of both regional communities experiencing technological issues with connection, with a moratorium on new systems connected to the network in Carnarvon and experiences with voltage fluctuations limiting solar adoption on some feeder lines in Narrogin. While these issues might be technical, it was expressed by a variety of stakeholder groups that there were a number of institutional impediments to technical challenges being addressed, including a lack of finances committed to solving technical issues and a lack of political oversight of network operators to encourage network solutions to renewable energy problems. Finally, some community members, network operators and a public sector worker indicated on-going concerns relating to the appropriate regulation of solar suppliers and installers, with the quality of solar installations continuing to be an issue for residential consumers in both metropolitan and regional communities [23].

It is worth noting the clear distinction between these two policy categories and the kinds of policies that could be actioned by different stakeholder groups (Fig. 2). Local and regional governments could commit to providing policy solutions for market acceptance, with evidence to suggest local governments were already undertaking these policies where practicable. For example, the Gascoyne Development Commission had an incentive scheme available to Carnarvon consumers installing solar systems and Narrogin had renewable demonstration projects. However, the majority of policy suggestions, and those deemed to be most important in increasing the penetration of solar energy, were those that addressed socio-political acceptance. These policies could only be implemented by the state government, and therefore rely heavily on the will of the Minister for Energy and the Premier for implementation. The results of this research therefore indicate that identification of socio-political barriers by those informing Cabinet, acceptance of these barriers by Cabinet members and significant political pressure to encourage government to promote solar (and other forms of renewable energy) ahead of incumbent generation and institutions "locked in" to the energy sector will be required to increase the penetration of renewable energy.

\section{Conclusions}

This research has identified that while a majority of stakeholders believe that they have the potential to influence solar policy this is based on an expectation of policy influence at the parliamentarian level. However, parliamentarians, along with public sector workers, indicated that they have little influence over policy outside of Cabinet. Where influence does exist it is in the form of information provision. Similarly, local government representatives are prevented from implementing policies for the promotion of solar energy in the absence of funds and political support from the community. Policy influence was possible where coalitions of community, industry and renewable energy advocates could come together with a single policy message delivered through the media, petitions and engagement with parliamentarians. It was identified that although local and regional government could implement policies to promote solar adoption these would only address barriers to market acceptance, while socio-political barriers to adoption are increasingly prevalent. This research highlights that policy influence is concentrated in positions of power within governments and that advocating for policies to address socio-political barriers will be increasingly necessary to increase the penetration of residential solar energy and renewable energy more generally.

The author thanks her supervisor for his support during this research. The author acknowledges the Australian Government's support, through the provision of an Australian Postgraduate Award. The researcher thanks Chunbo Ma and Michael Burton, of the School of Agricultural and Resource Economics, University of Western Australia and the Australian Research Council for partial funding of this research. The researcher also thanks members of the solar industry, government officials and the residents of Carnarvon and Narrogin who gave their time for this project. The researcher thanks the two anonymous peer reviewers for their feedback on an earlier version of this paper.

The author was employed as an energy policy officer for the Western Australian Government from 2009 to 2012. The author will not benefit financially from the publication of this paper.

\section{References}

1. Australian Government, Australian Government Response to the Climate Change Authority's 2014 Renewable Energy Target Review (2015), Available from: https://www.envi ronment.gov.au/climate-change/publications/aust-govt-re sponse-cca-2014-ret-review (last consulted on: 2016/15/09)

2. T. Nelson, P. Simshauser, S. Kelley, Australian residential solar feed-in tariffs: industry stimulus or regressive form of taxation? Econ. Anal. Policy 41, 113 (2011)

3. G. Simpson, J. Clifton, Testing diffusion of innovations theory with data: financial incentives, early adopters, and distributed solar energy in Australia, Energy Res. Soc. Sci. 29, 12 (2017)

4. G. Simpson, J. Clifton, The emperor and the cowboys: the role of government policy and industry in the adoption of domestic solar microgeneration systems, Energy Policy 81, $141(2015)$

5. R. Wüstenhagen, M. Wolsink, M.J. Bürer, Social acceptance of renewable energy innovation: an introduction to the concept, Energy Policy 35, 2683 (2007)

6. Clean Energy Regulator, Postcode data for small-scale installations (2017), Available from: http://www.cleanenergyr egulator.gov.au/RET/Forms-and-resources/Postcode-datafor-small-scale-installations (last consulted on: 2017/05/07) 
7. G. Simpson, J. Clifton, Subsidies for residential solar photovoltaic energy systems in Western Australia: distributional, procedural and outcome justice, Renew. Sustain. Energy Rev. 65, 262 (2016)

8. R. Haas et al., Socio-economic aspects of the Austrian $200 \mathrm{kWp}$-photovoltaic-rooftop programme, Solar Energy 66, 183 (1999)

9. M. Wolsink, The research agenda on social acceptance of distributed generation in smart grids: renewable as common pool resources, Renew. Sustain. Energy Rev. 16, 822 (2012)

10. G. Simpson, J. Clifton, Consultation, participation and policy-making: evaluating Australia's renewable energy target, Austr. J. Public Admin. 73, 29 (2014)

11. D. Cook, Consultation, for a change? Engaging users and communities in the policy process, Soc. Policy Admin. 36, 516 (2002)

12. D. Tayal, V. Rauland, Future business models for Western Australian electricity utilities, Sustain. Energy Technol Assess. 19, 59 (2017)

13. Government of Western Australia, Electricity in Western Australia (2017), Available from: https://www.finance.wa. gov.au/cms/Public_Utilities_Office/Energy_in_Wester n_Australia/Electricity/Electricity_in_Western__Austra lia.aspx (last consulted on: 2017/30/06)

14. Horizon Power, Who we are (2017), Available from: https:// horizonpower.com.au/about-us/overview/who-we-are/ (last consulted on: 2017/09/07)

15. Synergy, Who we are (2017), Available from: https://www. synergy.net.au/About-us/Who-we-are (last consulted on: $2017 / 09 / 07)$
16. Economic Regulation Authority, Can I choose my retailer? (2017), Available from: https://www.erawa.com.au/gas/ switched-on-energy-consumers-guide/can-i-choose-my-retail er (last consulted on: 2017/09/07)

17. Government of Western Australia, Government electricity corporations (2017), Available from: http://www.treasury.wa. gov.au/Public-Utilities-Office/Electricity-industry/Govern ment-electricity-corporations/ (last consulted on: 2017/09/07)

18. Australian Bureau of Statistics, 2011 Census (2013), Available from: http://www.abs.gov.au/websitedbs/cen sushome.nsf/home/census?opendocument\&navpos=10 (last consulted on: 2017/13/02)

19. J. Allen, W.R. Sheate, R. Diaz-Chavez, Community-based renewable energy in the Lake District National Park - local drivers, enablers, barriers and solutions, Local Environ. 17, $261(2012)$

20. QSR International Pty Ltd, NVivo qualitative data analysis software (2015)

21. Barnett C, Media statement: feed-in tariff decision reversed (2013), Available from: https://www.mediastatements.wa. gov.au/Pages/Barnett/2013/08/Feed-in-Tariff-decision-re versed.aspx (last consulted on: 2014/07/10)

22. Solar Citizens, Barnett's massive solar betrayal (2013), Available from: http://www.solarcitizens.org.au/barnett_ betrayal (last consulted on: 2014/07/10)

23. Clean Energy Regulator, Statistical analysis of inspection sample (2015), Available from: http://www.cleanenergyre gulator.gov.au/DocumentAssets/Pages/Statistical-analy sis-of-inspection-sample-June-2015.aspx (last consulted on: $2017 / 05 / 07)$

Cite this article as: Genevieve Simpson, Solar power and policy powerlessness - perceptions of persuasion in distributed residential solar energy policy development, Renew. Energy Environ. Sustain. 2, 14 (2017) 